\title{
Recycling of Wastewater into Useable Water by using Natural Materials
}

\author{
Akshay Jagannath Rajagopal \\ Student \\ School of Civil Engineering \\ Sastra Deemed to be University
}

\author{
Jeyaprakash S \\ Student \\ School of Civil Engineering \\ Sastra Deemed to be University
}

\begin{abstract}
Due to the fall in levels of rainfall as well as scarcity of water year by year in Tamil Nadu, our main aim is to reduce the natural water required for the growth of vegetable crops, using the treated sewage water. This process is done using natural materials like Tamarind Seed, Ash of the Rice Husk, Charcoal, Moringa Oleifera Seed (Drumstick Seed) and Fine Sand. For this project we have collected Sewage Water from our College Sewage Treatment Plant and we have done filtration. The filtration process is done by aeration method using fish tank motor for 20 minutes. After filtration, the water is allowed to settle down for another 20 minutes and then the water is transferred to the next filter. The same process is continued up to the last filter. In the last filter there is fine sand in the top layer and charcoal in the bottom layer. In this filter the filtration process is done by gravitational force. The natural materials were selected by studying each of their properties. The chemical properties of the treated water were analyzed for pH, Turbidity, COD and BOD. These values were compared with the values of the raw sewage water. The volumetric efficiency of the filter was also checked based on the water obtained after the treatment process. On analyzing these properties and from various studies we have found that this treated water can be used for agricultural purposes such as growing vegetable crops, nutrition crops etc. Based on our studies we have found that this water can be used for spinach, flat beans, ridged gourd, broccoli etc.
\end{abstract}

Key Words- Sewage Water, Vegetable Crop, Rice Husk, Charcoal, Moringa Oleifera Seed Powder, Tamarind Seed Powder

INTRODUCTION: -

India faces major environmental challenges associated with waste generation and inadequate waste collection, transport, treatment, and disposal. Current systems in India cannot cope-up with the volumes of waste generated by an increasing urban population, this impacts on the environment and public health. The challenges and barriers are significant, but so are the opportunities. The priority is to move from reliance on waste dumps that offer no environmental protection, to waste management systems that retain useful resources within the economy. Waste segregation at source and use of specialized waste processing facilities to separate recyclable materials that plays a vital role.

Based on various studies the treated water is good for vegetation purposes. The treated water is used for growing nutrition crops and vegetable crops such as flat beans, spinach, ridged gourd, peas, broccoli, and eggplant. Using the treated wastewater not only reduces the water and land pollution but also reduces the water required for growing crops up to $60 \%$. This method of agriculture can be used when there is drought in an area as well as during summer seasons. This method can also be used for roof farming and for gardening purposes.

\section{METHODOLOGY: -}

The setup of the filter is given below.

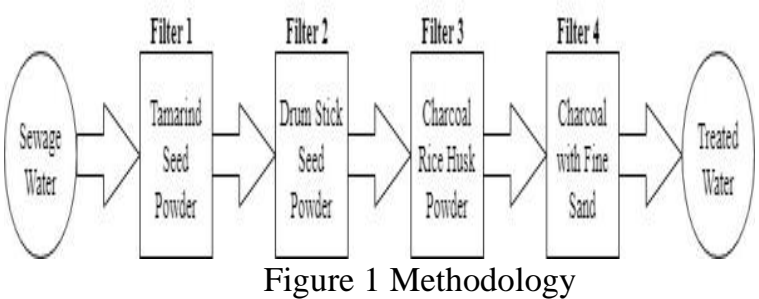

The tamarind seed powder in filter 1 is prepared using the following method:

Step 1: Tamarind seed is soaked in water for about 3 hours. Step 2: The soaked tamarind seed is left to dry under the sun for about a day. Step 3: Finally, the tamarind seed is finely grinded, and it is allowed to dry in room temperature for about an hour.

The drum seed powder in filter 2 is prepared by this method: Step 1: Dry drumstick seed is left under the sun for 5-6 hours. Step 2: Then, it is finely grinded and let in room temperature for 30 minutes.

The charcoal rice husk in filter 3 is prepared by taking the waste rice husk and then it is burnt. This is used in filter 3 . In filter 4, the fine sand is taken from river side. In filter 4, the charcoal is in the bottom layer while the fine sand is in the top layer. The sewage water is directly poured into the filter 1 . The filtration process begins here and the method which is followed is aeration method. For aeration to be done we use fish tank motor. The filters are connected using pvc pipe.

The design of the filter is given below.

Shape - Rectangular

Length $-43.1 \mathrm{~m}$

Width $-58 \mathrm{~m}$

Length to width ratio $-3: 4$

Area of the filter $-2500 \mathrm{~m}^{2}$

Depth of filter media $-1 \mathrm{~m}$

Effective size of filter media $-0.4 \mathrm{~mm}$

Uniformity co-efficient of filter media -5

Rate of hydraulic loading - 95 litres/day $/ \mathrm{m}^{2}$

Number of units -4

Breeding period of sewage -24 hours ( 1 day) 
When is sewage water is poured to filter 1 , the motor is switched on and the aeration is done for 20 minutes. After 20 minutes of aeration, the water is allowed to settled down for 20 minutes. This is done for removing the hard metals and the turbidity is removed up to $85 \%$. The hard metals are settled as sediments which is thrown out while transferring to filter 2. In filter 2 the hardness of the water is removed while the aeration is done for 20 minutes. Then it is allowed to settle down for 20 minutes and transferred to filter 3 . In filter 3 also aeration is done for 20 minutes and settled down for 20 minutes. In this filter the BOD is removed, color is changed, and the odor is removed. Also, the $\mathrm{pH}$ of the water is changed. It is transferred to the last filter. In this filter the aeration is not done but the water is allowed to be settled down for 20 minutes which removes all the waste particles. The efficiency of the filter is calculated.

After that, the treated water is collected in a container (bottle). Then the treated water is tested for $\mathrm{pH}$, BOD, turbidity, and COD.

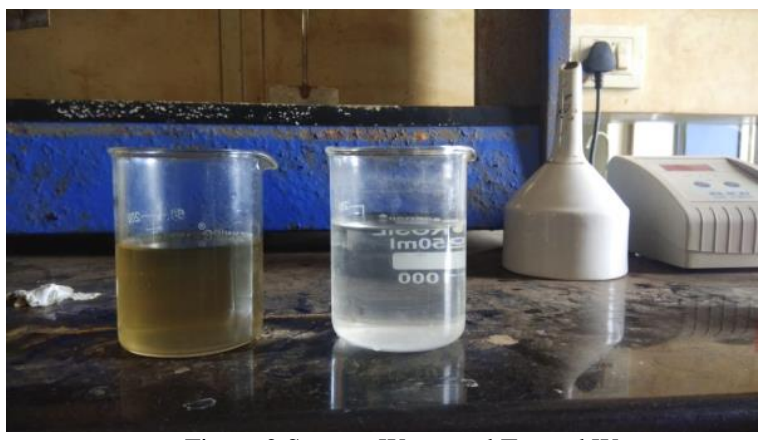

Figure 2 Sewage Water and Treated Water

The crops were chosen based on the available conditions present in the place. The available soil conditions are Soil is Alluvial, $\mathrm{pH}$ of the soil is 6.5-8.4 and the temperature of the place is between $25^{\circ} \mathrm{C}$ to $32^{\circ} \mathrm{C}$. The crops that were used are Spinach, Flat Beans and Ridged Gourd. The water required for each crop is given in the table below-

\begin{tabular}{|l|l|l|}
\hline Crop & Watering Period & Water Required \\
\hline Spinach & 30 days & $10 \mathrm{ml} /$ day \\
\hline Flat Beans & $12-16$ weeks & $15 \mathrm{ml} /$ day \\
\hline Ridged Gourd & $45-60$ days & $10 \mathrm{ml}$ for $3-4$ days \\
\hline
\end{tabular}

Watering is done for 16 days and the growth of the crops is observed.

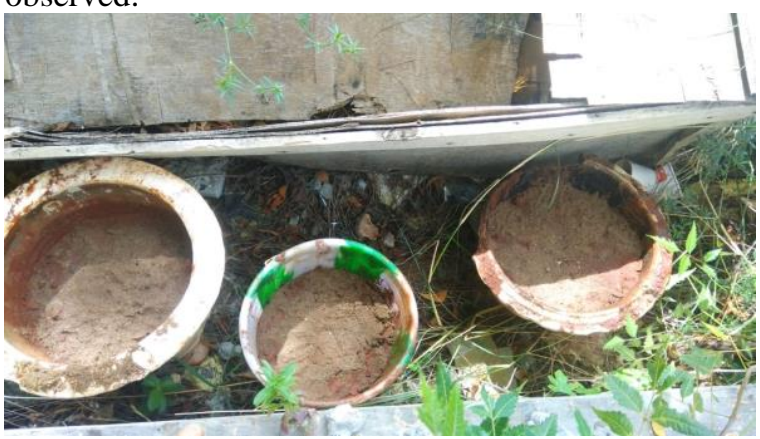

Figure 3 Day 1 of watering

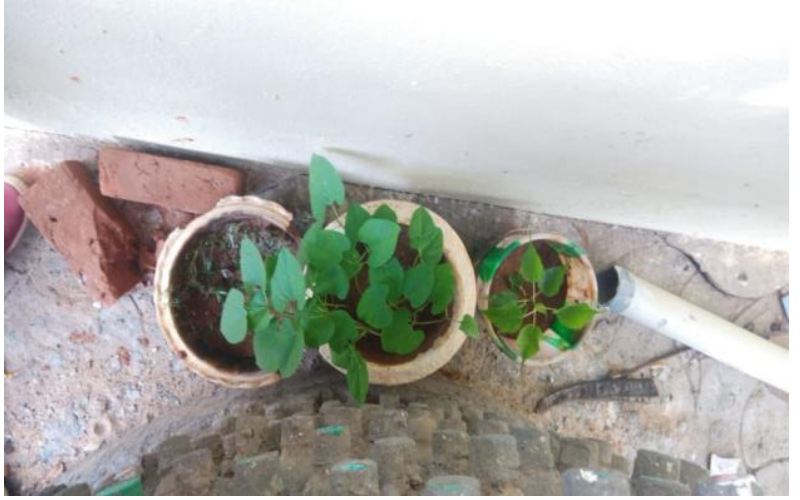

Figure 4 Day 16 of watering

\section{Calculation: -}

Amount of sewage water taken $(A)=6$ litres

Amount of treated water obtained $(B)=5.1$ litres

Efficiency of the filter $=\frac{B}{A} * 100 \%$

Efficiency of the filter $=(5.1 / 6) * 100 \%$

Efficiency of the filter $=85 \%$

\section{RESULTS AND DISCUSSIONS: -}

1. The efficiency of the filter is $85 \%$.

2. The value of $\mathrm{pH}$, turbidity, BOD and COD of the wastewater before and after treatment are as follows-

\begin{tabular}{|l|l|l|}
\hline Experiment & Sewage Water & Treated Water \\
\hline $\mathrm{pH}$ & 9 & 7.29 \\
\hline Turbidity & - & $12.36 \mathrm{NTU}$ \\
\hline BOD & $350 \mathrm{mg} / \mathrm{l}$ & $10.62 \mathrm{mg} / \mathrm{l}$ \\
\hline COD & $740 \mathrm{mg} / \mathrm{l}$ & $15.04 \mathrm{mg} / \mathrm{l}$ \\
\hline
\end{tabular}

\section{CONCLUSION: -}

The present study has been carried out to evaluate and characterize the quality of sewage water after treatment mainly for agricultural purposes. The changes in water quality before and after treatment is obtained and compared with water properties required for agriculture. The efficiency of the filter was also obtained. On comparing, we have found that this water is suitable for agricultural purposes mainly for cultivating vegetable crops. The vegetable crops were chosen based on the soil property and it has been cultivated and watering is done based on water required. The crops have shown good improvement on day to day progress.

\section{REFERENCES: -}

[1] Camila Emanuelle Mendonça Viana, José Wilmar da Silveira Neto and Khaldoon A. Mourad, (2016), Experiment using Rice Husk in Brazil, IJEPM Publication, 2, 15-21.

[2] Tan Chu Shan, Manaf Al Matar, Essam A. Makky and Eman N Ali, (November 2016) The use of Moringa oleifera seed as a natura coagulant for wastewater treatment and heavy metals removal, Springer Publication, 1369-1377.

[3] Hendrawati, Indra Rani Yuliastri, Nurhasni, Eti Rohaeti, Hefni Effendi and Latifah K Darusman, (2016), The use of Moringa Oleifera Seed Powder as Coagulant toImprove the Quality of Wastewater and Ground Water, IOP Conf. Series: Earth and Environmental Science 31, 175-185.

[4] M. Murugan and E. Subramanian, (2006), Studies on defluoridation of water by Tamarind seed an unconventional biosorbent, IWA Publication, 453-462.

[5] Ronke Ruth Ayangunna, Saidat Olanipekun Giwa and Abdulwahab Giwa, (2016) Coagulation-Flocculation Treatment of 
Industrial Wastewater Using Tamarind Seed Powder, International Journal of ChemTech Research IJCRGG Publication, 9, 771-780.

[6] Leslie Miller-Robbie, Anu Ramaswami and Priyanie Amerasinghe, (2017), Wastewater treatment and reuse in urban agriculture: exploring the food, energy, water, and health nexus in Hyderabad, India, 214-226.

[7] Adriel Ferreira da Fonseca, Uwe Herpin, Alessandra Monteiro de Paula, Reynaldo Luiz Victória and Adolpho José Melfi, (2007), Agricultural use of treated sewage effluents: agronomic and environmental implications and perspectives for Brazil, Sci. Agric, 64, 194-209.

[8] Patil Rohan R, Jagadale Suryakant S, Gaikwad Aniket A, Mane Aniket V, Anekar NR and Awasare SD, (2017), Use of Moringa Oleifera seed as Natural Coagulant, 10, 336-340 